\title{
The herpes simplex virus-1 Us3 protein kinase blocks CD8T cell lysis by preventing the cleavage of Bid by granzyme B
}

\author{
A Cartier ${ }^{1}$, E Broberg $^{2}$, T Komai ${ }^{3}$, M Henriksson ${ }^{1}$ and \\ MG Masucci ${ }^{\star}, 1$ \\ ${ }^{1}$ Microbiology and Tumor Biology Center, MTC Karolinska Institutet, Box 280, \\ Stockholm S-171 77, Sweden; \\ 2 Department of Virology, University of Turku, Turku, Finland; \\ 3 Sankyo CO, 2-58 Hiromachi 1-Chome, Shinagawa-Ku, Tokyo, Japan \\ * Corresponding author: MG Masucci. Tel: + 46-8-2786755; \\ Fax: + 46-8-331399; E-mail: maria.masucci@mtc.ki.se
}

Received 26.3.03; revised 26.6.03; accepted 27.6.03; published online 8 August 2003 Edited by $\mathrm{C}$ Bleackley

\begin{abstract}
The Us3 kinase is part of the antiapoptotic arsenal that salvages herpes simplex virus (HSV)-1-infected cells from damage caused by different stimuli. We demonstrate that Us 3 protects HSV-1-infected cells from lysis by MHC class Irestricted CD8T cells without affecting antigen presentation. Expression of Us3 was associated with inhibition of caspase activation and reduced cleavage of the proapoptotic protein Bid. Recombinant granzyme B (GrB) failed to cleave Bid in cytosolic extracts from Us3 positive cells, while recombinant Bid served as substrate for Us3 phosphorylation, suggesting that modification of Bid by Us3 blocks its processing by GrB. Our data illustrate a new strategy of viral escape, where modification of a cellular proapoptotic substrate may prevent lysis of the infected cells without affecting other T-cell functions.

Cell Death and Differentiation (2003) 10, 1320-1328, doi:10.1038/

sj.cdd. 4401308

Published online 8 August 2003
\end{abstract}

Keywords: herpes simplex virus; Us3 protein kinase; granzyme B; cytotoxic T cells; apoptosis; B lymphoblasts

Abbreviations: HSV, herpes simplex virus; Us3, unique short 3; GrB, granzyme B; CTL, cytotoxic T cell; LCL, lymphoblastoid cell line; MHC, major histocompatibility complex

\section{Introduction}

The immune response is tough on viruses that must survive and multiply in the infected host for a sufficient period of time in order to allow successful transmission to susceptible individuals. The relationship with the immune system is particularly challenging for herpes viruses that establish latent infections in immunocompetent carriers, which explains why members of this virus family have evolved various means to curb host defenses in order to maintain latency and achieve replication in the face of strong resident immunity (reviewed in $\mathrm{Nash}^{1}$ ).
The herpes simplex virus (HSV) is a classical example of the complex interaction between herpes viruses and the immune system. Infections with HSV types 1 and 2 are ubiquitous, with a prevalence of more than $90 \%$ and approximately $50 \%$ in adults, respectively. ${ }^{2}$ Primary skin or mucosal infection is usually followed by transmission, via sensory nerves, to the spinal or trigeminal ganglia where life-long latency occurs. Subsequent intermittent reactivation is followed by retrograde transport to the epithelia, where a new round of replication results in the production of infectious virus. Neutralizing antibodies and antiviral CD4 and CD8T cell responses effectively inhibit virus replication at mucosal sites and in the nervous system, but fail to achieve virus eradication (reviewed in Dahershia $^{3}$ ).

Studies in animal models emphasize the pivotal role of CD8T cells in the control of primary HSV-1 infection in sensory ganglia. ${ }^{4}$ Spread of the virus to the nervous system is accompanied by infiltration of CD8T cells that persist for long time after the resolution of acute infection. ${ }^{5}$ In immunocompetent mice, this correlates with rapid termination of virus replication with little evidence of neuronal destruction, while in animals lacking CD8T cells virus clearance is delayed and accompanied by a striking loss of neurons. ${ }^{4}$ Treatment of explants of trigeminal ganglia from infected mice with anti-CD8 antibodies causes accelerated reappearance of reactivating virus, ${ }^{6}$ suggesting that CD8T cells may be capable of controlling virus replication without damaging the infected cells.

Induction of apoptosis via the $\mathrm{Ca}^{2+}$-dependent exocytosis of cytotoxic granules is the primary mechanism by which CD8T cells control virus infection. ${ }^{7,8}$ Granzyme B (GrB), the principal serine protease involved in this process, is known to cleave several cellular substrates including the executioner caspase, caspase-3. Caspase-3 activates the caspase-activatable DNAse (CAD), which enters the nucleus where it cleaves DNA into 200 base pair fragments leading to cell death. ${ }^{9-12}$ CTLs can also induce apoptosis by crosslinking Fas on the target cell surface. This interaction culminates in the recruitment and activation of caspase-8 via the adapter molecule Fasassociated death domain (FADD). The activated caspase-8 induces cell death by activating caspase-3. Recently, it was shown that these two pathways converge at the mitochondria since both $\mathrm{GrB}$ and caspase- 8 cleave Bid, producing a truncated form that induces membrane depolarization, leading to the release of proapoptotic proteins such as cytochrome $c$.

HSV-1 has evolved multiple mechanisms to protect infected cells from destruction by CTLs. The HSV-1 protein ICP47 has been shown to interact with the transporter associated with antigen processing (TAP), which blocks the binding and translocation of antigenic peptides to the ER and their subsequent loading onto MHC class I molecules for presentation at the target cell surface. HSV-1-infected cells were also shown to resist apoptosis induced by MHC class II-restricted CD4T cells. ${ }^{13}$ Two HSV-1 gene products, Us5 and Us3, were 
shown to inhibit apoptosis induced via Fas triggering or UV irradiation, respectively, ${ }^{14}$ but their mechanism of action is poorly understood. The Us5 protein was shown to prevent the activation of caspase-3 by purified GrB. ${ }^{15}$ The Us3 gene encodes a tegument-associated protein kinase that phosphorylates serine/threonine residues. ${ }^{16}$ Us3 was shown to inactivate the proapoptotic protein Bad by post-translational modification, but the details of this interaction remain unknown. ${ }^{17}$ Here, we demonstrate that Us3 protects HSV-1infected cells from lysis by MHC class I-restricted CD8T cells without affecting antigen presentation or T-cell triggering. Expression of Us3 correlated with blockade of the caspase cascade and phosphorylation-dependent inhibition of Bid cleavage by $\mathrm{GrB}$. Using stable transfectants that express Us3 under the control of a tetracycline-regulated inducible promoter, we demonstrate that expression of Us3 in the absence of other viral proteins is sufficient to block Bid cleavage. We also show that Us3 phosphorylates Bid in vitro. The evolution of a viral antiapoptotic product that selectively inactivates cytotoxic responses without affecting other T-cell functions points to a specific role of nonlytic $T$ cells in the biology of HSV-1 infection.

\section{Results}

\section{Expression of Us3 protects target cells from lysis by CD8T cells}

To investigate whether the expression of Us3 could protect target cells from lysis by CD8T cells, EBV carrying LCLs derived from HLA A11-positive individuals were infected with wild-type HSV-1, Us3-deleted (Us3-del) and Us3-repair (Us3rep) strains, and then exposed to $T$ cells specific for the immunodominant A11-restricted epitope in the EBV nuclear antigen EBNA4. Optimal conditions for HSV-1 infection of the LCLs were established by monitoring the expression of the immediate early protein ICP4, the late protein gC, and Us3 in virus titration (not shown) and kinetics assays. As shown in Figure 1a, cells infected for $17 \mathrm{~h}$ at an m.o.i. of 10 with the wildtype Us3-del and the Us3-rep strains expressed equal levels of the ICP4 and gC proteins, whereas Us3 was not detected in cells infected with the Us3-del strain, as expected. The kinetics of ICP4 expression measured by immunofluorescence staining with the anti-ICP4 antibody at 3, 6, 17 and $24 \mathrm{~h}$ of infection demonstrated that between 80 and $90 \%$ of infected cells expressed this immediate early antigen at $17 \mathrm{~h}$ when most of the cells were still viable (not shown). This time point was therefore chosen for all subsequent experiments.

The effect of Us3 expression on the sensitivity of HSV-1infected cells to lysis by HLA A11-restricted CTLs was investigated in ${ }^{51} \mathrm{Cr}$ release assays. A lower level of killing was observed with LCLs infected with the wild-type and Us3rep strains over a wide range of effector: target ratios, while cells infected with the Us3-del strain were lysed as efficiently as the uninfected controls (Figure 1b). The protective effect of Us3 was highly significant, since approximately 10-fold higher numbers of effectors were required for equal lysis of Us3expressing cells as compared to uninfected controls or cells infected with Us3-deleted virus. The effect was reproducibly observed with LCLs derived from different donors (Figure 1c;
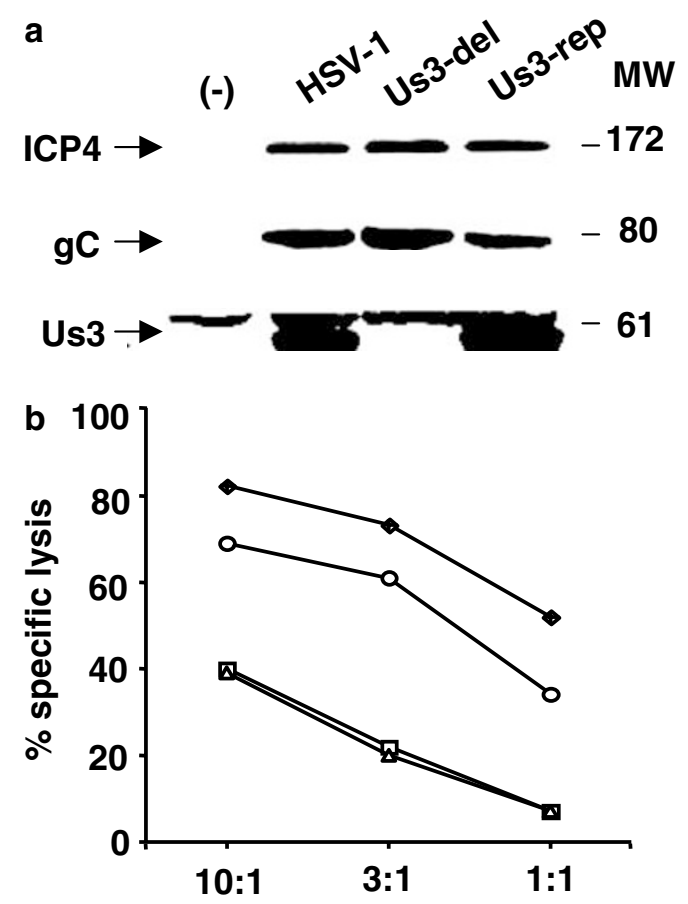

Effector : Target ratio



Figure 1 Expression of HSV-1 protects LCLs from CTL lysis. (a) The SI LCL was infected with wild-type HSV-1, Us3-del and Us3-rep strains at an m.o.i. of 10 for $17 \mathrm{~h}$ at $37^{\circ} \mathrm{C}$, and protein expression was assessed by Western blot analysis of total cell lysates probed with antibodies against HSV-1 ICP4, gC and Us3. The specific bands migrating at 172,80 and $55 \mathrm{kDa}$, respectively, are indicated. (b-c) Sensitivity of HSV-1-infected LCLs to lysis by HLA class I-restricted CTLs. The percentage of specific lysis was measured in $4 \mathrm{~h}^{51} \mathrm{Cr}$ release assays. (b) One representative experiment out of six, using the JAC LCLs is shown. Uninfected - -, HSV-1 - $\triangle$-, Us3-del -O-, Us3-rep - $\square-$. (c) Comparison of CTL lysis between $B K$ and JAC LCLs. Mean \pm S.D. of three and four experiments, respectively, at an effector : target ratio of $3: 1 ;(-)=$ uninfected

not shown). Furthermore, similar results were obtained with polyclonal CTL cultures and with CTL clones specific for a second HLA A11-restricted epitope, as well as effectors specific for other HLA class I : peptide combinations (not shown).

\section{Expression of Us3 does not alter target antigenicity and effector triggering}

Since ICP47 has been shown to enable HSV-1 immune escape by modulating antigen processing and presentation, ${ }^{18}$ 
we tested whether Us3 may affect target antigenicity and/or Tcell triggering. Biochemical and immunological assays were used to study the surface expression of HLA A11-peptide complexes. HLA class I molecules were immunoprecipitated $17 \mathrm{~h}$ postinfection from metabolically labeled cells using the $\mathrm{W} 6 / 32 \mathrm{mAb}$, that recognizes a common determinant expressed on all class I alleles, and individual polypeptides were resolved by 1D-IEF. As illustrated in Figure 2a, equal levels of surface class I molecules were immunoprecipitated from the uninfected and HSV-1-infected LCLs, suggesting that the surface expression of HLA class I was not significantly affected at the time of our cytotoxicity assays. This finding was further confirmed by immunofluorescence staining and FACS analysis, using the mAb W6/32 (Figure 2b) and antibodies specific for monomorphic determinants on individual class 1 alleles (not shown).

We then tested whether the Us3-mediated inhibition of cytotoxicity might reflect a general failure of T-cell activation. The effector cells were cocultured with HSV-1-infected and uninfected LCLs for $3 \mathrm{~h}$, and the amount of TNF $\alpha$ released in the supernatant was measured by induction of cell death in actinomycin-D-treated WEHI 164 mouse fibroblasts. As shown in Figure 2c, virus-infected and uninfected LCLs were equally potent inducers of TNF $\alpha$ release, irrespective of Us3 expression. Thus, the inhibition of T-cell lysis does not involve modifications of target cell antigenicity.


Figure 2 Us3 expression does not affect antigen presentation. LCLs were infected with wild-type HSV-1, Us3-del and Us3-rep strains at an m.o.i. of 10 for $17 \mathrm{~h}$ at $37^{\circ} \mathrm{C}$. (a) Surface MHC class I measured by $1 \mathrm{D}-\mathrm{IEF}$ in the SI LCL. HLA class I polypeptides were immunoprecipitated from lysates of metabolically labeled cells with the mAb W6/32. The HLA class I heavy chains and $\beta_{2} \mathrm{~m}$ bands were identified by comparison with a panel of previously characterized cell lines. One representative experiment out of three is shown. (b) MHC class I expression was detected by immunofluorescence staining and FACS analysis of SI, BK, FY and MIN LCLs stained with the mAb W6/32. Uninfected $\mathbf{\Delta}$, HSV-1 网, Us3-del $\square$, Us3-rep $\mathbf{\square}$. (c) Induction of TNF $\alpha$ release was measured by incubating the CTLs with HSV-1-infected BK LCL for $3 \mathrm{~h}$. The amount of TNF $\alpha$ released in the supernatant was measured by the capacity to inhibit growth of the TNF $\alpha$ sensitive WEHI 164 cell line. Mean \pm S.D. of three experiments. Control $\mathbf{a}$ and CTLs $\mathbf{\Delta} ;(-)=$ uninfected

\section{Expression of Us3 inhibits T-cell-induced activation of caspases}

Experiments with inhibitors of caspases have strongly implicated these enzymes as essential components of the T-cell death execution machinery. In accordance, infection of the BK LCL with the wild-type or Us3-rep viruses caused 83 and $90 \%$ reduction of $\mathrm{T}$-cell-induced activation of caspase-3 relative to the uninfected $\mathrm{LCL}$, while the reduction was significantly lower, $26 \%$ on average, in cells infected with the Us3-del strain (Figure 3a). The activation of caspase-8 and -9 was also measured, since these caspases are known to process and activate caspase-3. Fluorimetric assays using specific fluorogenic substrates showed that caspase-8 and -9 activities were both reduced by $89 \%$ in BK LCL infected with wild-type HSV-1, by 93 and $77 \%$ in BK LCL infected with Us3rep, and by 48 and $37 \%$ in the LCL infected with the Us3-del strain, respectively (Figure $3 b, c)$. Similar results were obtained for caspase activity in uninfected and HSV-1infected JAC LCL (Figure 3a-c). Comparable levels of caspase activities were obtained when the $T$ cells were pretreated with caspase inhibitors before exposure to the

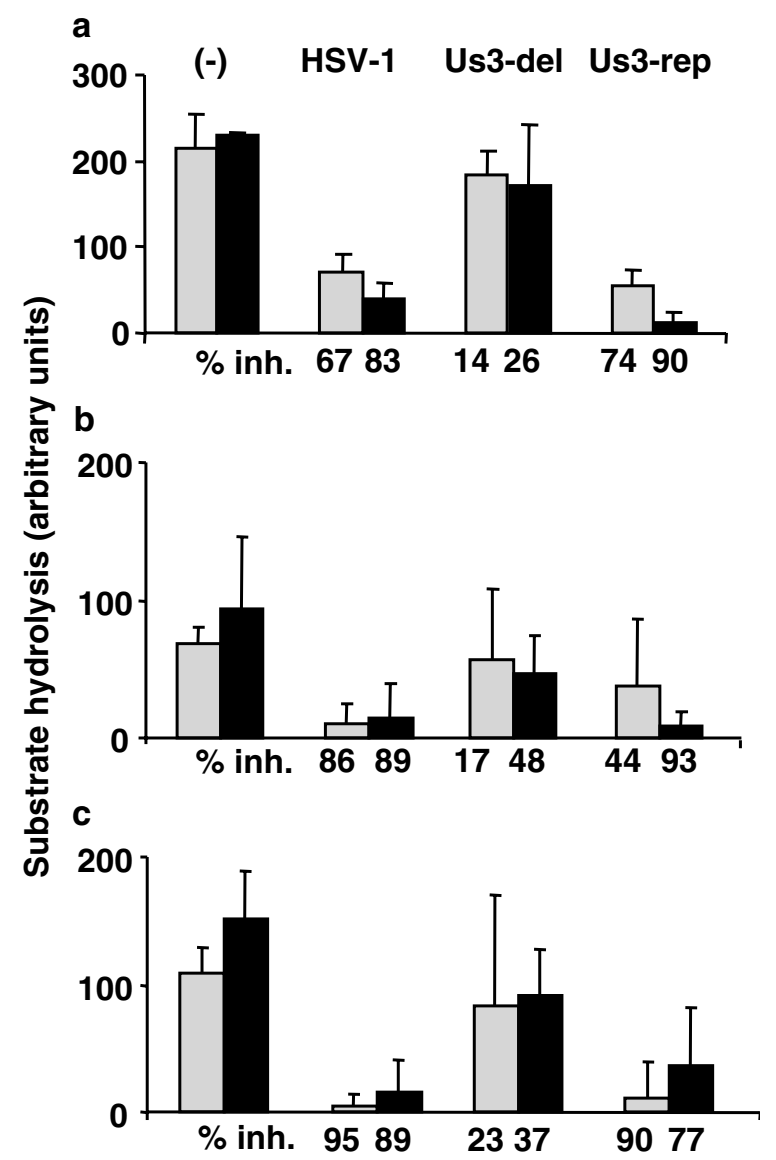

Figure 3 CTL-induced activation of caspases in HSV-1-infected LCLs. JAC and BK LCLs were infected with wild-type HSV-1, Us3-del and Us3-rep strains, and then incubated with CTLs for $1 \mathrm{~h}$ at an effector : target ratio of 3:1. Caspase-3 (a),-8 (b) and -9 (c) activation was measured by fluorimetric assay using specific fluorogenic substrates. Fluorescence was detected at excitation $400 \mathrm{~nm}$ and emission $505 \mathrm{~nm}$. Mean \pm S.D. of three experiments. JAC $\square$, BK $\square$; $(-)=$ uninfected; \% inh $=\%$ inhibition 
Table 1 T-cell-induced cleavage of Bid in lymphoblasts infected with the wild-type and mutant HSV-1 strains ${ }^{a}$

\begin{tabular}{|c|c|c|c|c|}
\hline \multirow[b]{2}{*}{ Exp } & \multicolumn{4}{|c|}{$\%$ Bid cleavage ${ }^{\mathbf{b}}$} \\
\hline & Uninfected & HSV-1 & Us3-del & Us3-rep \\
\hline 1 & 53 & 24 & 84 & 24 \\
\hline 2 & 91 & 59 & 80 & 66 \\
\hline 3 & 46 & 33 & 52 & 29 \\
\hline 4 & 50 & 0 & 67 & 11 \\
\hline 5 & 60 & 8 & 26 & 14 \\
\hline Mean \pm S.E. ${ }^{c}$ & $60 \pm 9$ & $25 \pm 12$ & $62 \pm 12$ & $30 \pm 11$ \\
\hline
\end{tabular}

aLCLs were infected with wild-type HSV-1, Us3-del and Us3-rep strains at an m.o.i. of 10 for $17 \mathrm{~h}$ at $37^{\circ} \mathrm{C}$

${ }^{\mathrm{b}}$ The percentage of CTL-induced Bid cleavage was measured at an effector: target ratio of $3: 1$. ' $S t a n d a r d$ error

targets, confirming that the observed activities were mainly, if not exclusively, contributed by the target cells (not shown).

\section{Us3 blocks T-cell and GrB-induced activation of Bid}

Although caspases are substrates for GrB cleavage in vitro and in vivo, recent data suggest that the proteolytic activation of Bid is the first GrB-mediated event in T-cell induced apoptosis. ${ }^{19}$ We therefore examined whether the expression of Us3 affected the cleavage of Bid in targets exposed to specific CTLs. Uninfected LCLs and LCLs infected with Us3positive or -negative HSV-1 strains were cocultured with the CTLs for $1 \mathrm{~h}$ at $3: 1$ effector : target ratio, and the expression of Bid was then monitored by Western blotting. Exposure to specific CTLs resulted in significant reduction of the intensity of a polypeptide corresponding to the full-length inactive Bid in uninfected targets (Figure $4 \mathrm{a}$ ). This reduction was an LCLspecific phenomenon, since endogenous Bid was not detected in CTLs under the conditions of the assays. The effect was significantly lower in LCLs infected with the wildtype and Us3-rep viruses, suggesting that the proteolytic activation of Bid is inhibited in Us3-expressing cells. Densitometric analysis of Western blots confirmed that the expression of Us3 correlated with reduction of Bid cleavage from more than $60 \%$ in the uninfected cells to approximately $25 \%$ (Table 1). In order to investigate the role of $\mathrm{GrB}$, uninfected targets were cocultured with CTLs in the presence of $20 \mu \mathrm{M}$ of the $\mathrm{GrB}$ inhibitor $\mathrm{z}-\mathrm{AAD}-\mathrm{CH}_{2} \mathrm{Cl}$ for the entire duration of the experiment. GrB inhibitor had no toxic effect on CTLs, since cells incubated with the inhibitor alone were still viable. However, the CTL-induced cleavage of Bid was abolished under these conditions (Figure 4b), confirming that $\mathrm{GrB}$ is the main effector of Bid cleavage. This was further substantiated by the demonstration that the cleavage of Bid was not affected when the target cells were exposed to CTLs in the presence of 50 and $100 \mu \mathrm{M}$ of the caspase inhibitor z-VAD-FMK (Figure 4c).

We then asked whether the failure to activate Bid could be ascribed to an Us3-dependent modification of sensitivity to GrB cleavage. Cytosolic extracts from uninfected and HSV-1infected LCLs were incubated for $1 \mathrm{~h}$ at $37^{\circ} \mathrm{C}$ with increasing amounts of recombinant $\mathrm{GrB}$, and the residual uncleaved Bid was quantified by densitometry in Western blots probed with an anti-Bid antibody. A dose-dependent cleavage of Bid was observed in all samples (Figure 5a). However, while compar-
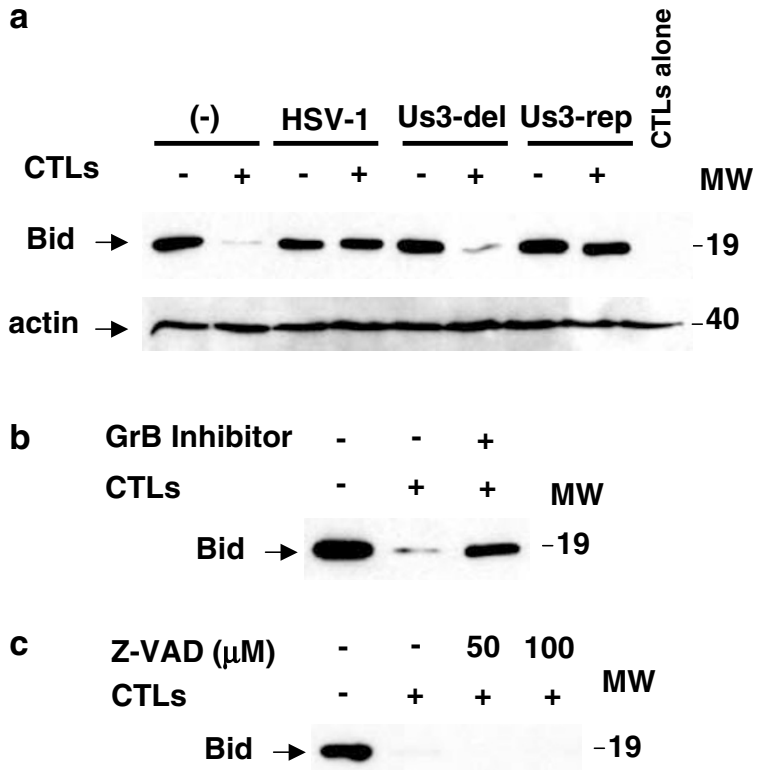

Figure 4 Expression of Us3 inhibits the cleavage of Bid. (a) The CTL-induced cleavage of Bid in uninfected and HSV-1-infected BK LCLs was measured after incubation of CTLs and target cells at an effector : target ratio of $3: 1$ for $1 \mathrm{~h}$. (b-c) Uninfected BK LCLs were cocultured with the CTLs in the presence or absence of z-AAD- $\mathrm{CH}_{2} \mathrm{Cl}$ (GrB inhibitor, b) or z-VAD-FMK (general caspase inhibitor, c). (a-c) Bid cleavage was assessed in Western blots with a Bid-specific antibody. One representative experiment out of five and three is shown for $(\mathbf{a}, \mathbf{b})$ and $(\mathbf{c})$, respectively; $(-)=$ uninfected

able amounts of enzyme were required for $50 \%$ cleavage in extracts from uninfected and Us3-del-infected cells, an approximately 10 -fold higher amount of enzyme was required for $50 \%$ cleavage in extracts of cells infected with the wild-type and Us3-rep viruses (Table 2; data not shown). In order to test whether Us3 can act in the absence of other HSV-1-encoded proteins, the experiment was repeated using the HEp-2 cell line and a HEp-2/Us3 subline that expresses the Us3 gene from a tetracycline-regulated promoter. Since the endogenous Bid cannot be detected by standard immunochemistry procedures, HEp-2 and HEp-2/Us3 cells were transfected with a plasmid encoding the wild-type murine Bid gene $24 \mathrm{~h}$ before induction of Us3 expression by tetracycline treatment. Cleavage of Bid was then assessed by incubating cytosolic extracts with increasing amounts of recombinant $\mathrm{GrB}$ for $1 \mathrm{~h}$ at $37^{\circ} \mathrm{C}$. As shown in Figure $5 \mathrm{~b}$, two- to four-fold higher amounts of $\mathrm{GrB}$ were required for equal levels of Bid cleavage in 
extracts of Us3-expressing cells, confirming that expression of Us3 alone is sufficient for blocking GrB activation of Bid.

\section{Us3 phosphorylates Bid in vitro}

Previous work has suggested that phosphorylation by casein kinases I and II may protect Bid from cleavage by caspase$8^{20}$ To investigate whether a similar mechanism may explain the Us3-induced resistance of Bid to GrB cleavage, lysates from the uninfected and HSV-1-infected LCLs were pretreated with Lambda protein phosphatase for $30 \mathrm{~min}$ at $37^{\circ} \mathrm{C}$ before addition of recombinant GrB. As shown in Figure 6a, pretreatment with Lambda protein phosphatase had no effect on the level of Bid cleavage in lysates from the uninfected cells treated with $10 \mathrm{ng}$ of $\mathrm{GrB}$. In contrast, the inhibition of Bid cleavage observed when HSV-1-infected lysates were treated with $\mathrm{GrB}$ was completely reversed by pretreatment with the phosphatase. Treatment of lysates with Lambda protein phosphatase alone had no affect on the endogenous level of Bid; thus, phosphorylation seems to play an important role in the inhibition of GrB-mediated Bid cleavage in the HSV-1infected cells.

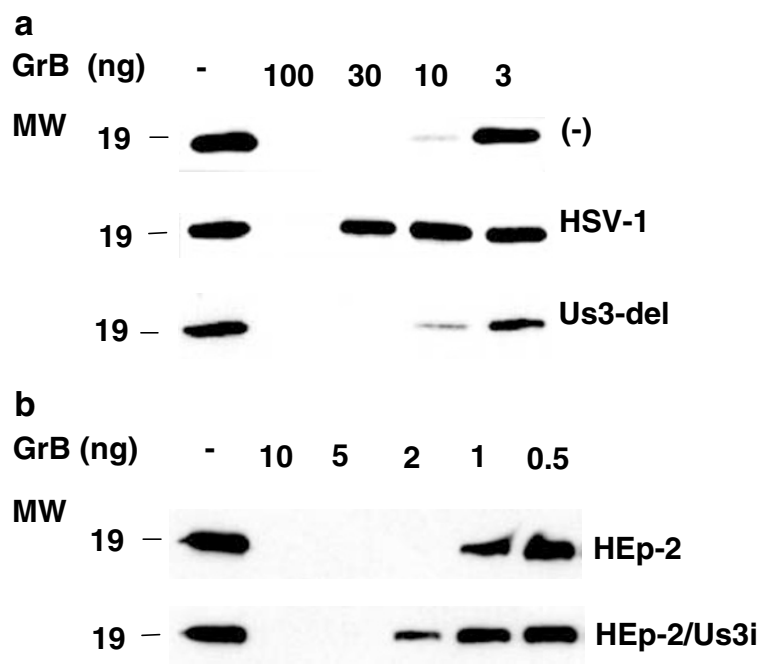

Figure 5 Us3 protects Bid from cleavage by GrB. Cytosolic extracts (100 $\mu \mathrm{g})$ from BK LCLs infected with wild-type HSV-1, Us3-del and Us3-rep strains (a), or HEp-2 and HEp-2/Us3i cells (b), were incubated with the indicated amounts of purified $\mathrm{GrB}$ for $1 \mathrm{~h}$ at $37^{\circ} \mathrm{C}$. GrB-induced Bid cleavage was assessed by Western blotting. One representative experiment out of four is shown; $(-)=$ uninfected; $\mathrm{HEp}-2 / \mathrm{Us} 3 \mathrm{i}=\mathrm{HEp}-2 / \mathrm{Us} 3$ inducible
In the final set of experiments, we asked whether Us3 is directly responsible for Bid phosphorylation. To this end, the capacity of recombinant human Bid to serve as substrate for Us3 immunoprecipitated from transfected HEp-2/Us3 cells was tested in in vitro kinase assays. Mock immunoprecipitates from HEp-2 cells were used as specificity controls. As shown in Figure 6b, Bid was phosphorylated in the presence of Us3 in a dose-dependent manner. A band of the same molecular weight was also observed when the kinase assay was run in the presence of mock immunoprecipitates from HEp-2 cells. However, the intensity of this band was significantly weaker and did not increase over a 15-fold increase in the amount of the mock immunoprecipitate. In line with the reported autophosphorylation capacity of Us $3,{ }^{21}$ a band corresponding to the size expected for phosphorylated Us3 was observed when the kinase reaction was run in the presence of immunoprecipitates from Us3-positive cells. The identity of

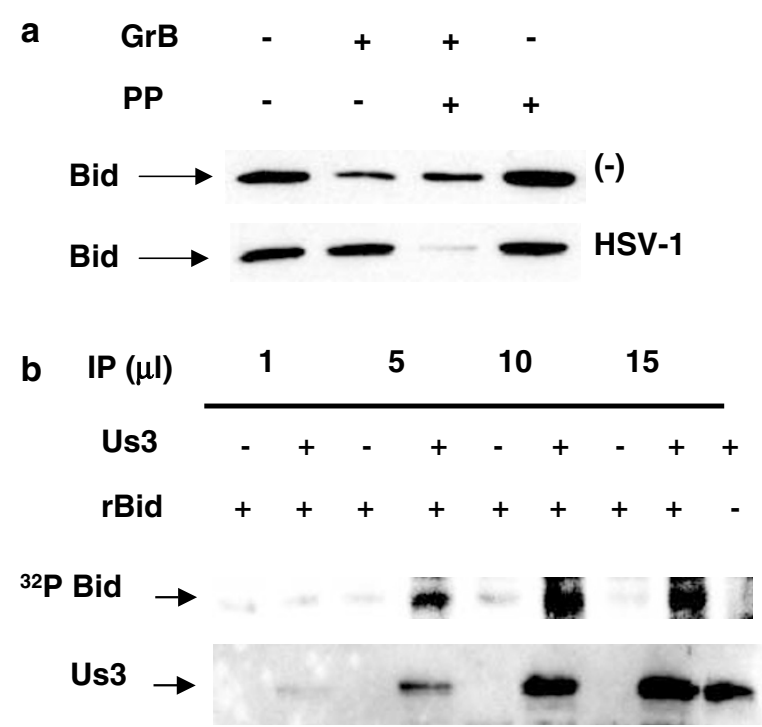

Figure 6 Phosphorylation of Bid mediates protection from GrB cleavage. (a) Cytosolic extracts $(100 \mu \mathrm{g})$ from BK LCLs uninfected or infected with wild-type HSV- 1 were pretreated with $0.5 \mathrm{mg} / \mathrm{ml}$ Lambda protein phosphatase before incubating with $10 \mathrm{ng}$ of GrB. GrB-induced Bid cleavage was assessed by Western blotting. One representative experiment out of four is shown. (b) Us3mediated phosphorylation of Bid. The indicated amounts of Us3 immunoprecipitates from stably transfected HEp-2/Us3 cells were used to phosphorylate recombinant human Bid in in vitro kinase assays. Mock immunoprecipitates were obtained from Us3-negative HEp-2 cells. Polypeptides corresponding to phosphorylated Bid and Us3 are indicated by arrows. One representative experiment out of three is shown; $(-)=$ uninfected; $\mathrm{PP}=$ Lambda protein phosphatase

Table 2 GrB-induced cleavage of Bid in cytosolic extracts of lymphoblasts infected with the wild-type and mutant HSV-1 strains ${ }^{\mathrm{a}}$

\begin{tabular}{lcccc}
\hline & \multicolumn{3}{c}{ \% Bid cleavage $^{\mathbf{b}}$} \\
\cline { 2 - 5 } GrB (ng) cell lysate & $\mathbf{3}$ & $\mathbf{1 0}$ & $\mathbf{3 0}$ & $\mathbf{1 0 0}$ \\
\hline Uninfected & $45 \pm 8$ & $93 \pm 0.7$ & $98 \pm 1$ & $99 \pm 1$ \\
HSV-1 & $1 \pm 1$ & $8 \pm 4$ & $31 \pm 24$ & $98 \pm 1$ \\
Us3-del & $39 \pm 24$ & $55 \pm 14$ & $89 \pm 13$ & $96 \pm 2$
\end{tabular}

aLCLs were infected with wild-type HSV-1 and Us3-del strains at an m.o.i. of 10 for $17 \mathrm{~h}$ at $37^{\circ} \mathrm{C}$.

${ }^{\mathrm{b}} \mathrm{The} \%$ Bid cleavage was calculated as the ratio between the intensity of the specific band in cell lysates incubated without or with addition of the indicated amounts of purified GrB. Mean \pm S.E. of three experiments 
this band was confirmed in Western blots using the Us3 antibody (Figure 6b).

\section{Discussion}

We have identified the HSV-1 protein kinase Us3 as a major regulator of immune effector functions. Using a genetic approach based on deletion/rescue of the Us3 gene from wild-type HSV-1, we demonstrate that Us3 is required for inhibition of apoptosis induced by CD8T cell, and provide evidence for a mechanism of action involving the phosphorylation of Bid and protection of this proapoptotic protein from proteolytic activation by GrB.

The current model for cytotoxic T-cell-induced apoptosis highlights the role of granule exocytosis and the release of GrB. Once in the cytosol, GrB induces a limited activation of caspases and directly cleaves Bid. The truncated Bid induces depolarization of the mitochondrial membrane and release of cytochrome $c$, which is then responsible for the further activation of caspases to the lethal threshold required for cell death. ${ }^{19,22}$ Consistent with this model, inhibition of GrB blocked the proteolytic activation of Bid in LCLs exposed to specific CTLs, while an inhibitor of caspases had no significant effect (Figure 4), thus confirming that cleavage of Bid by $\mathrm{GrB}$ is a rate-limiting event in the CTL-triggered proteolytic cascade that leads to target cell death. In accordance, inhibition of CTL lysis by Us3 correlated with approximately $50 \%$ reduction in the cleavage of Bid, and significantly decreased activation of caspase-8, -9 and -3 (Figures 3, 4; Table 1). It should be stressed that, while LCLs are not a physiological target for HSV-1, these cells express much higher levels of HLA class I than epithelial or neuronal cells, and are much more efficient antigen-presenting cells; thus, the degree of protection achieved by Us3 expression in these cells is likely to be an underestimate of what can be achieved under physiologic conditions. The central role of Bid in GrB-induced apoptosis and the significance of blockade of this proapoptotic pathway in the context of virus infection in vivo are challenged by the recent finding that $\mathrm{GrB}$ can cause cell death in Bid knockout mice. ${ }^{23}$ However, while it seems likely that multiple salvage pathways would be activated to compensate for the lack of Bid in transgenic animals, emphasizing thereby the plasticity and adaptability of the apoptotic machinery in a living organism, such backup mechanisms are unlikely to become available in the context of an acute or reactivating virus infection due to the immediacy of CTL responses and concomitant inhibition of target cell physiology induced by the virus.

Several lines of evidence support the notion that modification of Bid by Us3 is a key event in protection from CTLinduced apoptosis. First, a 10-fold reduction in the cleavage of Bid was observed when exogenous GrB was added to cytosolic extracts from Us3-positive cells (Figure 5a; Table 2), confirming that Bid is protected from proteolysis. Expression of Us3 in the absence of other viral proteins was sufficient for the effect (Figure 5b), suggesting that Us3 may modify Bid either directly or indirectly through the activity of a cellular intermediate. Interestingly, the activation of caspases by GrB was not affected under the same conditions (data not shown), suggesting that Bid is selectively modified. Most importantly, treatment of lysate from Us3-expressing cells with Lambda protein phosphatase reconstituted the cleavability of Bid by GrB (Figure 6a), implicating phosphorylation as an important mechanism for protection. Finally, recombinant Bid served as a direct substrate for Us3 phosphorylation in vitro (Figure 6b). Relevant to this observation is the report by Desangher et al. $^{20}$ that Bid becomes resistant to cleavage by caspase-8 upon phosphorylation by casein kinases I and II, which prevents apoptosis induced by Fas ligation in type II cells. Although phosphorylation by these cellular kinases did not prevent the cleavage of Bid by GrB, these findings point to phosphorylation as a common mechanism for regulation of Bid activation. Interestingly, we have shown that expression of Us3 is associated with the appearance of phosphorylated Bad species, and Bad serves as substrate for Us3-dependent phosphorylation in vitro. ${ }^{24}$ Thus, Us3 appears to target several cellular proteins implicated in the mitochondrial pathway of apoptosis.

The putative sites of Us3-dependent phosphorylation of Bid remain to be determined. Using murine Bid, Desagher et al. ${ }^{20}$ have shown that casein kinase-dependent inhibition of cleavage involves the phosphorylation of Bid at Ser and Thr residues located in close proximity to the caspase-8 cleavage site at Asp59. The GrB cleavage site is located downstream of this residue at Asp75, which may explain why this cleavage is not affected. Interestingly, two Ser residues are present in close proximity of the GrB cleavage site at positions 76 and 78 of the murine Bid. These residues are conserved in the human Bid that also contains Arg residues in position 68, 71, 84, and 88. This basic environment is compatible with the extremely basic consensus sequence proposed for the Us3 phosphorylation site. ${ }^{16}$ It is noteworthy that the expression of Us3 did not correlate with any detectable shift in Bid mobility (Figures 4-6 and not shown). This is probably because Bid is constitutively phosphorylated and must be dephosphorylated for inducing apoptosis. ${ }^{20}$ Thus, phosphorylation by Us3 may counteract the activity of phosphatases that are activated by exposure to different stress signals, including encounter with cytotoxic cells.

A key aspect of our work is the demonstration that HSV-1 infection interferes with the activity of CTLs before the appearance of virus-induced changes in surface MHC class I expression or antigen presentation. Most importantly, HSV1 -infected cells were equally potent inducers of cytokine production, confirming that T-cell recognition was not impaired. This illustrates an important feature of the interaction of HSV-1 with the host immune system. The finding that ICP47 exerts a broad inhibition on the presentation of $\mathrm{MHC}$ class I-restricted epitopes by interfering with the activity of TAP was taken to suggest that CD8T cells may play a relatively minor role in the control of virus infection. ${ }^{25}$ In line with this possibility, the immunohistology of cutaneous herpetic lesions has shown that infiltration begins with CD4T cells that recognize numerous viral products and secrete large amounts of IFN- $\gamma$, while CD8T cells appear only later during the infection. ${ }^{26}$ However, evidence from murine models suggest that the situation may be different in the nervous system, where CD8T cells are critical for the initial control of virus replication and for the maintenance of latent infection in 
the sensory ganglia. ${ }^{4}$ Paradoxically, the presence of this cell type was shown to protect neuronal cells from extensive damage, suggesting that they may act through a noncytolytic mechanism. Our findings provide a mechanistic explanation for how HSV-1 may selectively block the lethal consequence of CD8T cell activation without affecting other functions. The 'partial inactivation' induced by the viral kinase is likely to provide a double advantage, since a significant loss of neurons due to unchecked virus replication would be deleterious for the host, and would also limit the access of the virus to potential sites of latency. It is noteworthy that while expression of Us3 is nonessential for viral replication in vitro, $^{16,27}$ an HSV-1 mutant lacking Us3 was virtually nonpathogenic on intracerebral inoculation, ${ }^{28}$ and an Us3deleted HSV-2 displayed a highly reduced neuroinvasiveness. ${ }^{29}$ Neuroinvasiveness was reconstituted in mice immunosuppressed by treatment with cyclophosphamide, confirming that the modulation of immune functions is an important component of Us3 activity in vivo. Collectively, our findings highlight a new facet of the interaction of herpes viruses with their infected host, where the maintenance of noncytolytic immunity may be the key to the establishment of latent infections.

\section{Materials and Methods}

\section{Reagents}

Recombinant human TNF $\alpha$ was purchased from Boehringer Mannheim Scandinavia AB (Bromma, Sweden). The caspase inhibitors z-DEVDFMK, z-LETD-FMK, and z-LEHD-FMK, z-VAD-FMK, the caspase substrates Ac-DEVD-AFC, Ac-LETD-AFC, Ac-LEHD-AFC, purified GrB and $z-A A D-\mathrm{CH}_{2} \mathrm{Cl}$ were purchased from Enzyme Systems Products, Livermore, CA, USA. Monoclonal mouse antibodies (mAbs) anti HSV-1 ICP4 and -gC were obtained from Rumbaugh-Goodwin Institute, Plantation, FL, USA. A polyclonal rabbit anti-Us3 serum was produced by immunizing rabbits with a semi-purified GST-Us3 fusion protein. Culture supernatant from the mouse hybridoma $W 6 / 32^{30}$ was used to detect total MHC class I. A polyclonal rabbit anti-Bid antibody ${ }^{31}$ was the kind gift from Dr. X Wang (University of Texas Southwestern medical Center at Dallas, Dallas, TX, USA). Recombinant human Bid was obtained from R\&D systems, Minneapolis, MN, USA.

\section{Cell lines}

The HLA A11-positive lymphoblastoid cell lines (LCLs) JAC, BK, MIN and SI were generated by infection with Epstein-Barr Virus (EBV) as previously described. ${ }^{32}$ A stable Us3-expressing subline of the epithelial cell line HEp-2 (HEp-2/Us3) was generated by transfection with the pBKCMV-Us3 plasmid that contains the Us3 coding region under the control of the cytomegalovirus immediate early promoter. Transfected cells were maintained in DMEM medium containing $1.2 \mathrm{mg} / \mathrm{ml}$ of geneticin (Sigma, Saint Louis, MI, USA). The HEp-2/Us3i cell line that expresses a tetracycline-regulated Us3 gene was generated by transfection of HEp-2 cells with pTRE-neo-Us3 and pTet-On-pur plasmids (Invitrogen, Groningen, Netherlands) using lipofectamine, and the transfected cells were selected in medium containing $0.5 \mathrm{mg} / \mathrm{ml}$ of Geneticin and $0.4 \mu \mathrm{g} / \mathrm{ml}$ of puromycin (SIGMA, Saint Louis, MI, USA), respectively. The expression of Us3 was induced by treating cells with $0.5 \mu \mathrm{g} / \mathrm{ml}$ of doxycycline (SIGMA, Saint Louis, MO, USA) for $18 \mathrm{~h}$ at $37^{\circ} \mathrm{C}$, and Us3 expression was investigated in Western blots using an Us3-specific polyclonal rabbit antibody.

\section{Viruses}

The prototype wild-type HSV-1 strain, $F(16)$, the Us3 deletion strain R7041 that lacks a Pstl-BamHI fragment encoding amino acids 69-357 of Us3 (Us3-del) and Us3 repair strain 7306 (Us3-rep) ${ }^{33}$ were gifts of Bernard Roizman (The Marjorie B Kovler Viral Oncology Laboratories, University of Chicago). Virus stocks were prepared and titrated in Vero cells according to standard protocols.

\section{Western blots}

The cells were lysed in SDS-PAGE loading buffer, or in 0.5\% NP-40containing buffer, and protein concentration was determined by standard BSA assay. The cell lysates were fractionated by $8-15 \%$ SDS-PAGE. Dilutions $(1: 500)$ of antibodies against ICP4, gC, or Us3, or 1:4000 dilution of anti-Bid antibody were used to detect protein expression.

\section{Immunofluorescence}

Cells $\left(4 \times 10^{5}\right)$ were spotted on glass slides, fixed in ice-cold methanol, and then stained with 1:500 dilution of the anti-ICP $4 \mathrm{mAb}$ followed by $1: 25$ dilution of a FITC-conjugated $F(a b)_{2}$ fragment of rabbit anti-mouse immunoglobulin (DAKO A/S, Denmark). The fluorescence was analyzed with a fluorescence microscope (Nikon Eclipse E400, Japan).

\section{Cytotoxic assays}

HLA A11-restricted CTLs specific for the epitopes IVTDFSVIK (IVT) and AVFDRKSDAK (AVF) of the EBV nuclear antigen 4 (EBNA 4) were generated and maintained as described previously. ${ }^{34}$ Cytotoxicity was measured in standard $4 \mathrm{~h}{ }^{51} \mathrm{Cr}$-release assays at $10: 1,3: 1$, and $1: 1$ effector : target ratios in triplicates.

\section{HLA class I expression}

Surface HLA class I expression was detected by staining with the W6/ $32 \mathrm{mAb}$, and fluorescence intensity was measured with a FACSort flow cytometer (Becton Dickinson, San Jose, CA, USA). For biochemical analysis, the cells were metabolically labeled overnight in methionine-free medium containing $50 \mu \mathrm{Ci} / \mathrm{ml}^{35}$ methionine and $5 \%$ FCS. The labeled cells were then reacted with the W6/32 $\mathrm{mAb}$ and extensively washed before lysis in NP-40 buffer $(0.5 \%$ (v/v) Nonidet P-40, $50 \mathrm{mM}$ Tris pH 7.4 and $5 \mathrm{mM} \mathrm{MgCl}_{2}$ ) for $30 \mathrm{~min}$ on ice. The immunocomplexes were recovered from equal amounts of trichloroacetic acid-precipitable radioactivity by adsorption to $100 \mu \mathrm{l}$ of Staph-A suspension. MHC class I polypeptides were resolved by one-dimensional isoelectric focusing (ID-IEF) and detected by autoradiography. ${ }^{35}$

\section{TNF $\propto$ release assay}

LCLs were incubated with CD8T cells at an effector : target ratio of $3: 1$. The supernatants were collected after $3 \mathrm{~h}$, and the TNF $\alpha$ content of the supernatants was measured using the TNF $\alpha$-sensitive WEH 164 cell line. ${ }^{36}$ The concentration of TNF $\alpha$ in culture supernatants was deduced from a standard curve generated in each experiment using a serial dilution of recombinant TNF $\alpha$. 


\section{Enzymatic assays}

CD8T cells were preincubated for $1 \mathrm{~h}$ at $37^{\circ} \mathrm{C}$ with $50 \mu \mathrm{M}$ of the caspase inhibitors z-DEVD-FMK, z-LETD-FMK and z-LEHD-FMK, and then mixed with the targets at an effector:target ratio of $3: 1$. After cocultivation for $1 \mathrm{~h}$ at $37^{\circ} \mathrm{C}$, the cells were lysed and the supernatants were collected by centrifugation for $10 \mathrm{~min}$ at $14,000 \mathrm{rpm}$. Caspase-3, -8 or -9 activity was evaluated by addition of $20 \mu \mathrm{M}$ of the specific fluorogenic substrate. Substrate hydrolysis was measured after incubation for $1 \mathrm{~h}$ at $37^{\circ} \mathrm{C}$ using a luminescence spectrometer (Perkin Elmer, CT, USA) at $400 \mathrm{~nm}$ excitation and $505 \mathrm{~nm}$ emission.

\section{Bid cleavage and phosphorylation}

LCLs were incubated with the CTLs for $1 \mathrm{~h}$ at an effector : target ratio of $3: 1$ in the presence or absence of $20 \mu \mathrm{M}$ of the GrB inhibitor z-AAD$\mathrm{CH}_{2} \mathrm{Cl}$ or 50 and $100 \mu \mathrm{M}$ of the general caspase inhibitor z-VAD-FMK. Alternatively, $100 \mu \mathrm{g}$ of cell lysates was incubated with 3-100 $\mathrm{ng}$ of $\mathrm{GrB}$ for $1 \mathrm{~h}$ at $37^{\circ} \mathrm{C}$. To assay the involvement of phosphorylation, lysates were pretreated with $500 \mathrm{U}$ of Lambda phosphatase for $30 \mathrm{~min}$ before addition of GrB. HEp-2 and HEp-2/Us3i cells were transfected with the wild-type mouse $\mathrm{Bid}^{27}$ using Lipofectamine (Life Technologies, Grand Island, NY, USA) according to the instructions of the manufacturer. After $24 \mathrm{~h}$, the HEp-2/Us3i cells were induced for Us3 expression by treatment with tetracycline. After additional $24 \mathrm{~h}$, Bid cleavage was assayed by incubating $100 \mu \mathrm{g}$ of cell lysates with $0.5-10 \mathrm{ng}$ of $\mathrm{GrB}$ for $1 \mathrm{~h}$ at $37^{\circ} \mathrm{C}$. The reactions were stopped by the addition of SDS-PAGE loading buffer. Bid cleavage was analyzed in Western blots, and the percentage of cleavage was assessed by densitometry. Us3 was immunoprecipitated from HEp-2/Us3 cells using the anti-Us3 rabbit serum. Mock precipitates from Us3-negative HEp-2 cells served as negative controls. The immunoprecipitates (1$15 \mu \mathrm{l})$ were used to phosphorylate $1 \mu \mathrm{g}$ of purified human recombinant Bid. The mixtures were incubated for $1 \mathrm{~h}$ at $30^{\circ} \mathrm{C}$ in $50 \mu \mathrm{l}$ kinase buffer (25 mM Tris-HCl pH 7.5, $5 \mathrm{mM} \beta$-glycerophosphate, $2 \mathrm{mM}$ DTT, $0.1 \mathrm{mM}$ $\mathrm{Na}_{3} \mathrm{VO}_{4}, 10 \mathrm{mM} \mathrm{MgCl}$ ) and $5 \mu \mathrm{Ci}\left[\gamma_{-}{ }^{32} \mathrm{P}\right]$-ATP $(3000 \mathrm{Ci} / \mathrm{mmol}$ ) (Amersham Pharmacia Biotech, Buckinghamshire, UK). The reactions were stopped by addition of SDS-PAGE loading buffer. Phosphorylated Bid was resolved by $15 \%$ SDS-PAGE and visualized by autoradiography.

\section{Acknowledgements}

We thank B Roizman, A Sharipo and X Wang for the kind gift of HSV-1 strains and specific antibodies and V Levitsky for the gift of EBV-specific cytotoxic $T$ cells. This investigation was supported by grants from the Swedish Cancer Society, the Swedish Foundation for Strategic Research and the Karolinska Institutet, Stockholm, Sweden.

\section{References}

1. Nash AA (2000) T cells and the regulation of herpes simplex virus latency and reactivation. J. Exp. Med. 191: 1455-1457

2. Cunningham AL, Mindel A and Dwyer DE (2000) Global epidemiology of sexually transmitted disease. In Sexually Transmitted Diseases Standberry L and Bernstein D (eds) (San Diego: Academic Press), pp. 3-42

3. Dahershia M, Feldman LT and Rouse BT (1998) Herpes virus latency and the immune response. Curr. Opin. Microbiol. 1: 430-435

4. Simmons A and Tscharke DC (1992) Anti-CD8 impairs clearance of herpes simplex virus from the nervous system: implication for the fate of virally infected neurons. J. Exp. Med. 175: 1337-1344
5. Shimeld C, Whiteland JL, Nicholls SM, Grinfeld E, Easty DL, Gao H and Hill TJ (1995) Immune cell infiltration and persistence in the mouse trigeminal ganglion after infection of the cornea with herpes simplex type-1. J. Neuroimmunol. 61: 7-16

6. Liu T, Khanna KM, Chen X, Fink DJ and Hendrix RL (2000) CD81T cells can block herpes simplex virus type 1 (HSV-1) reactivation from latency in sensory neurons. J. Exp. Med. 191: 1459-1466

7. Kagi D, Ledermann B, Burki K, Zinkernagel RM and Hengartner H (1996) Molecular mechanisms of lymphocyte-mediated cytotoxicity and their role in immunological protection and pathogenesis in vivo. Ann. Rev. Immunol. 14: 207-232

8. Atkinson EA and Bleackley RC (1995) Mechanisms of lysis by cytotoxic T cells. Crit. Rev. Immunol. 15: 359-384

9. Darmon AJ, Nicholson DW and Bleackley RC (1995) Activation of the apoptotic protease CPP32 by cytotoxic T-cell-derived granzyme B. Nature 377 : 446-448

10. Darmon AJ, Ley TJ, Nicholson DW and Bleackley RC (1996) Cleavage of CPP32 by granzyme $B$ represents a critical role for granzyme $B$ in the induction of target cell DNA fragmentation. J. Biol. Chem. 271: 21709-21712

11. Nicholson DW, Ali A, Thornberry NA, Vaillancourt JP, Ding CK, Gallant M, Gareau Y, Griffin PR, Labelle M and Lazebnik YA (1995) Identification and inhibition of the ICE/CED-3 protease necessary for mammalian apoptosis. Nature 376: 37-43

12. Tewari M, Quan LT, O'Rourke K, Desnoyers $S$, Zeng Z, Beidler DR, Poirier GG, Salvesen GS and Dixit VM (1995) Yama/CPP32 beta, a mammalian homolog of CED-3, is a CrmA-inhibitable protease that cleaves the death substrate poly(ADP-ribose) polymerase. Cell 81: 801-809

13. Jerome KR, Tait JF, Koelle DM and Corey L (1998) Herpes simplex virus type 1 renders infected cells resistant to cytotoxic T-lymphocyte-induced apoptosis. J. Virol. 72: 436-441

14. Jerome KR, Fox R, Chen Z, Sears AE, Lee H and Corey L (1999) Herpes simplex virus inhibits apoptosis through the action of two genes, Us5 and Us3. J. Virol. 73: 8950-8957

15. Jerome KR, Chen Z, Lang R, Torres MR, Hofmeister J, Smith S, Fox R, Froelich CJ and Corey L (2001) HSV and glycoprotein J inhibit caspase activation and apoptosis induced by granzyme B or Fas. J. Immunol. 167: 3928-3935

16. Purves FC, Longnecker RM, Leader DP and Roizman B (1987) Herpes simplex virus 1 protein kinase is encoded by open reading frame US3 which is not essential for virus growth in cell culture. J. Virol. 61: 2896-2901

17. Munger $J$ and Roizman B (2001) The US3 protein kinase of herpes simplex virus 1 mediates the posttranslational modification of $B A D$ and prevents $B A D$ induced programmed cell death in the absence of other viral proteins. Proc. Natl. Acad. Sci. USA 98: 10410-10415

18. Tortorella D, Gewurs BE, Furman MH, Schust DJ and Ploegh HL (2000) Viral subversion of the immune system. Ann. Rev. Immunol. 18: 861-926

19. Sutton VR, Davis JE, Cancilla M, Johnstone RW, Ruefli AA, Sedelies K, Browne KA and Trapani JA (2000) Initiation of apoptosis by granzyme B requires direct cleavage of Bid, but not direct granzyme B-mediated caspase activation. J. Exp. Med. 192: 1403-1414

20. Desagher S, Osen-Sand A, Montessuit S, Magnenat E, Vilbois F, Hochmann A, Journot L, Antonsson B and Martinou JC (2001) Phosphorylation of Bid by casein kinases I and II regulates its cleavage by caspase 8. Mol. Cell 8: 601611

21. Frame MC, Purves FC, McGeoch DJ, Marsden HS and Leader DP (1987) Identification of the herpes simplex virus protein kinase as the product of viral gene US3. J. Gen. Virol. 68: 2699-2704

22. Heibein JA, Swie Goping I, Barry M, Pinkoski MJ, Shore GC and Green DR (2000) Granzyme-B-mediated cytochrome $c$ release is regulated by the Bcl-2 family members Bid and Max. J. Exp. Med. 192: 1391-1401

23. Thomas DA, Scorrano L, Putcha GV, Korsmeyer SJ and Ley TJ (2001) Granzyme B can cause mitochondrial depolarization and cell death in the absence of BID, BAX, and BAK. Proc. Natl. Acad. Sci. USA 98: 14985-14990

24. Cartier A, Komai T and Masucci MG (2003) The Us3 protein kinase of Herpes simplex virus-1 block apoptosis by inducing phosphorylation of the Bcl2 family member Bad. Exp. Cell Res. in press

25. Hill A, Jugovic P, York I, Russ G, Bennink J, Yewdell J, Ploegh H and Johnson $D(1995)$ Herpes simplex virus turns off the TAP to evade host immunity. Nature 375: $411-415$ 
26. Cunningham AL, Turner RR, Meiller AC, Para MF and Merigan TC (1985) Evolution of recurrent herpes simplex virus lesions. J. Clin. Invest. 75: 226-233

27. Nishiyama $Y$, Yamada $Y$, Kurachi R and Daikoku T (1992) Construction of a US3 lacZ insertion mutant of herpes simplex virus type 2 and characterization of its phenotype in vitro and in vivo. Virology 190: 256-268

28. Meignier B, Longnecker R, Mavromara-Nazos P, Sears AE and Roizman B (1988) Virulence of and establishment of latency by genetically engineered deletion mutants of herpes simplex virus 1. Virology 162: 251-254

29. Yamamoto M, Kurachi R, Morishima T, Kito J and Nishiyama $Y$ (1996) Immunohistochemical studies on the transneuronal spread of virulent herpes simplex virus type 2 and its US3 protein kinase-deficient mutant after ocular inoculation. Microbiol. Immunol. 40: 289-294

30. Barnstable CJ, Bodmer WF, Brown G, Galfre G, Milstein C, Williams AF and Ziegler A (1978) Production of monoclonal antibodies to group A erythrocytes, $\mathrm{HLA}$ and other human cell surface antigens - new tools for genetic analysis. Cell 14: 9-20

31. Wang K, Yin XM, Chao DT, Milliman CL and Korsmeyer SJ (1996) BID: a novel BH3 domain-only death agonist. Genes Dev. 10: 2859-2869
32. Miller G and Lipman M (1973) Release of infectious Epstein-Barr virus by transformed marmoset leukocytes. Proc. Natl. Acad. Sci. USA 70: 190-194

33. Ejercito PM, Kieff ED and Roizman B (1968) Characterization of herpes simplex virus strains differing in their effects on social behavior of infected cells. J. Gen. Virol. 2: 357-364

34. Torsteinsdottir S, Masucci MG, Ehlin-Henriksson B, Brautbar C, Ben Bassat H, Klein $G$ and Klein E (1986) Differentiation-dependent sensitivity of human Bcell-derived lines to major histocompatibility complex-restricted T-cell cytotoxicity. Proc. Natl. Acad. Sci. USA 83: 5620-5624

35. Neefjes JJ, Breur-Vriesendorp BS, van Seventer GA, Ivanyi P and Ploegh HL (1986) An improved biochemical method for the analysis of HLA-class I antigens. Definition of new HLA-class I subtypes. Human Immunol. 16: 169181

36. Wei $\mathrm{CH}$, Yagita $\mathrm{H}$, Masucci MG and Levitsky V (2001) Different programs of activation-induced cell death are triggered in mature activated CTL by immunogenic and partially agonistic peptide ligands. J. Immunol. 166: 989-995 